\title{
Prolactinoma presenting with intermittent third nerve palsy
}

\author{
W N WYKES \\ From the St Woolos Hospital, Newport, Gwent
}

SUMmARY A patient presented with a painful third nerve palsy. This resolved spontaneously, but recurred several months later. At his second presentation carotid angiography gave normal results, but a high resolution CT scan showed a tumour in the right parasellar region. The serum prolactin was raised at over $22000 \mathrm{m \mu}$, showing this to be a prolactinoma.

A prolactinoma is not normally considered as a diagnosis in cases of painful third nerve palsy, the common causes being intracranial aneurysm, herpes zoster ophthalmicus, temporal arteritis, and migraine. A review of the literature revealed only one case report of a third nerve palsy caused by a prolactinoma, but that was neither isolated nor intermittent. ${ }^{1}$ However, pituitary tumours have been known to cause third nerve palsies before the diagnosis of prolactinoma was feasible. The unusual feature of the following case report, therefore, is that the patient's third nerve palsy was intermittent.

\section{Case report}

A 74-year-old woman presented in June 1983 with a right sided headache of five days' duration, an increased prominence of the left eye, and diplopia in all directions. Her previous medical history included thyrotoxicosis diagnosed in $\mathbf{1 9 6 4}$ for which she was initially treated with carbimazole (Neo-Mercazole) followed by a subtotal thyroidectomy. Dysthyroid exophthalmos and lid retraction of the left eye were noted at that time and had persisted since then. In 1972 the patient was found to be hypertensive, and antihypertensive treatment was begun.

Clinical findings on presentation in June 1983 consisted of $3 \mathrm{~mm}$ proptosis and lid retraction of the left eye, this appearance being exaggerated by a right ptosis, associated with a dilated right pupil with no direct or consensual response to light or accommodation, and paralysis of the right medial, superior, and inferior recti, with no evidence of function of the inferior oblique. The fourth and sixth nerves were

Correspondence to Mr W N Wykes, FRCS, St Woolos Hospital, Newport, Gwent NPT 4SZ. intact, and there were no other abnormal findings in the cranial nerves. In particular the visual fields were normal.

The patient was admitted immediately to hospital for bed rest and investigation of a possible right sided intracranial aneurysm. The ptosis and mydriasis cleared during the following week and the diplopia ceased, so that when reviewed by a neurologist on 13 July 1983 the patient was asymptomatic, and the only neurological finding was a $3 \mathrm{~mm}$ proptosis of the left eye. At this stage the neurologist did not consider that further investigation was justified.

Ten months later, in May 1984, the patient had an episode of weakness affecting her left arm for three hours and some intermittent numbness of her face. Her erythrocyte sedimentation rate (ESR) at this stage was $55 \mathrm{~mm} / \mathrm{h}$.

Within one month her right third nerve palsy returned, with increasingly severe right sided headache. The movements of the right eye were again severely limited, with a dilated pupil and partial ptosis. Carotid angiography was undertaken, but no aneurysm was seen. The possibility of the recurrent third nerve palsy and the transient ischaemic attack both being due to temporal arteritis was considered, although the highest ESR recorded was $57 \mathrm{~mm} / \mathrm{h}$. However, a temporal artery biopsy specimen in November 1984 was normal. A high resolution CT scan of the orbit showed an enhancing lesion in the right parasellar region, with erosion of the right side of the dorsum sellae, which was displaced backwards. Scans through the pituitary fossa showed a tumour occupying the right side of the fossa and extending into the parasellar region. The floor of the fossa was thinned, with extension into the sphenoid sinus and backwards into the dorsum sellae (Fig. 1). 

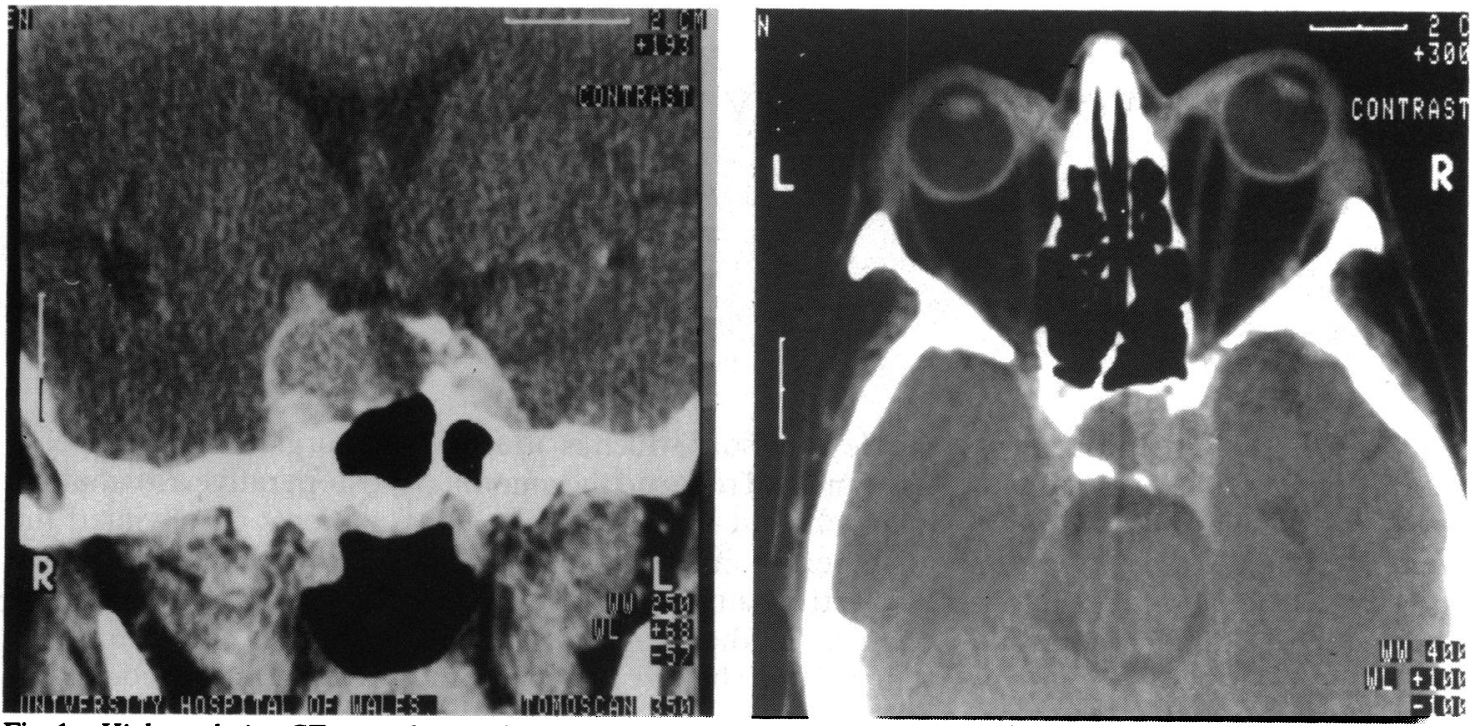

Fig. 1 High resolution CT scans showing lesion in right parasellar region.

It was considered at this stage that the appearance was most probably due to a malignant tumour, and therefore a course of radiotherapy was started. However, endocrine investigations showed a grossly raised prolactin level of over $22400 \mathrm{~m} \mu / 1$. Following radiotherapy the patient's prolactin level was greater than $5000 \mathrm{m \mu} / 1$, and a second CT scan showed no change. Treatment was changed to bromocriptine, which is known to be effective in reducing the size of prolactinomas. ${ }^{23}$ The patient had been on bromocriptine for two months at the latest review, but with no change in the signs.

\section{Discussion}

A review of the literature revealed only one case where a prolactinoma was associated with a third nerve palsy.' In that case the prolactinoma of a 51 -year-old woman had extended superiorly and laterally, causing both bitemporal visual field defects and a cavernous sinus syndrome. The patient recovered over a period of six months on bromocriptine therapy.

Prolactinomas commonly present in women in early reproductive life with problems of infertility, though they may present with any type of menstrual abnormality. ${ }^{45}$ Galactorrhoea may also occur (in $30-80 \%$ of cases). ${ }^{56}$ When the tumour presents as an expanding lesion, it usually causes visual field loss (in $7 \%$ of female cases). ${ }^{5}$ Men present later with impotence and obesity. ${ }^{78}$ However, our patient presented with a painful third nerve palsy, which was exceptional for being isolated and in particular for being intermittent.

I thank Mr A G Karseras, consultant ophthalmologist, for his help and encouragement in preparing this paper.

\section{References}

1 King LW, Molitch ME, Gittinger JW Jr, Wolpert SM, Stern J. Cavernous sinus syndrome due to prolactinoma: resolution with bromocriptine. Surg Neurol 1983; 19: 280-4.

2 McGregor AM, Scanlon MF, Hull R, Hall K. Effects of bromocriptine on pituitary tumour size. $\mathrm{Br}$ Med J 1979; ii: 700-3.

3 Wass JAH, Moult PJA, Thorner MO, et al. Reduction of pituitary tumour size in patients with prolactinomas and acromegaly treated with bromocriptine with or without radiotherapy. Lancet 1979; ii: 66-9.

4 Edwards CRW, Feek CM. Prolactinomas: a question of rational treatment. Br Med J 1981; 283: 1561-2.

5 Jacobs HS, Franks S, Murray MAF, Hull MGR, Steele SJ, Nabarro JDN. Clinical and endocrine features of hyperprolactinaemic amenorrhoea. Clin Endocrinol 1976; 5: 439-54.

6 Del Pozo E, Schalz KD, Wyss H, et al. Effect of prolactin on the mechanisms of ovulation and on pregnancy: some recent findings. In: Robyn C, Harter M, eds. Progress in prolactin physiology and pathology. Amsterdam: Elsevier/North Holland, 1978: 281-92.

7 Thorner MO, Edwards CRW, Hanker JP, Abraham G, Besser GM. Prolactin and gonadotrophin interaction in the male. In: Troen $\mathrm{P}$, Nankin $\mathrm{HR}$, eds. Testes in normal and infertile men. New York: Raven, 1977: 351-66.

8 Franks S, Jacobs HS, Martin N, Nabarro JDN. Hyperprolactinoma and impotence. Clin Endocrinol 1978; 8: 277-87.

Accepted for publication 7 January 1986. 